\title{
Electrocardiographic studies in different age groups of Nellore cross-breed sheep
}

\begin{abstract}
Aim: Present study was aimed to record the electrocardiography indices in different age groups of clinically healthy Nellore cross-breed sheep.

Background: Normal electrocardiographic studies of different species of animals help in detection of cardiac abnormalities and helpful while monitoring the vital parameters during the diseased conditions, treatment trails and operative procedures. Variations in the parameters were recorded in small ruminants based on the breed. Information pertaining to the electrocardiographic findings of Nellore cross-breed sheep was not documented.
\end{abstract}

Methodology: The present study was conducted at College of Veterinary Science, Proddatur, YSR Kadapa District of Andhra Pradesh, India from 2013 to 2016. Apparently, healthy local Nellore cross-breed sheep were categorized into five groups based on their age and in each group twenty sheep were included. The animals were examined prior to ECG recording and were proved to be clinically healthy. The electrocardiography was recorded on a bipolar base apex lead system. Duration and amplitude of the P, QRS complex and T wave and the PR, QT intervals and heart rate were measured and averaged from successive beats in lead I.

Results: Heart rate was $73.2 \pm 1.62$ in adults and it was $115.8 \pm 2.76$ in kids. The mean amplitude of $\mathrm{P}$ wave was $0.169 \pm 0.005 \mathrm{mV}$ in lambs and $0.177 \pm 0.005 \mathrm{mV}$ in the adult group. Mean duration of $\mathrm{P}$ wave, QRS complex and $\mathrm{T}$ wave was $0.044 \pm 0.003 \mathrm{sec}$, $0.066 \pm 0.003 \mathrm{sec}, 0.103 \pm 0.003 \mathrm{sec}$ in adult group and it was $0.041 \pm 0.006 \mathrm{sec}$, $0.063 \pm 0.003 \mathrm{sec}$ and $0.104 \pm 0.004 \mathrm{sec}$ in kids.

Conclusion: No significant difference was found in $\mathrm{P}$ wave amplitude, duration of $\mathrm{P}$ wave, QRS complex and $\mathrm{T}$ wave. The heart rate, an amplitude of ECG waves including QRS complex, T wave and duration of P-R, Q-T and R-R intervals showed the significant difference between the age groups. Heart rate was gradually decreased while aging and the negative correlation between age of the sheep and heart rate was noticed. This study provides information on the cardiac rhythm, heart rate, duration, and amplitude of ECG deflections in one of the common sheep breed in the YSR District of Andhra Pradesh.

Keywords: sheep, electrocardiography, heart rate, Nellore brown
Volume 6 Issue I - 2018

Sudhakara Reddy B, Sivajothi S
SriVenkateswara Veterinary University, India

Correspondence: Sivajothi S, College of Veterinary Science, Sri Venkateswara Veterinary University, Proddatur-516360, Andhra Pradesh, India, Email sivajothi579@gmail.com Received: December 16,2017 | Published: January 30,
2018

\section{Introduction}

Electrocardiography (ECG) is one of the non-invasive, inexpensive diagnostic techniques to detect the spread of the cardiac impulses. The electrocardiographic parameters have the greatest value in recognizing and diagnosing arrhythmias in animals. Different disease conditions lead to changes in the electrolyte balance. ${ }^{1}$ The majority of arrhythmias and conduction disturbances can be detected on clinical examination. ${ }^{2}$ For the physician, reference values are important to compare the results from diseased animals. Nellore cross-breed sheep is one of the common adapted breeds in the YSR District of Andhra Pradesh and it is the source for meat production which contributes significant economy to the formers (Figure 1). There are several kinds of literatures on electrocardiographic studies in different animals including in ruminants, but there is no previous study regarding the normal ECG parameters at different age groups in the Nellore cross breed sheep. ${ }^{3,4}$ The current study was done to provide ECG values and to evaluate the effects of age on these parameters in this breed.

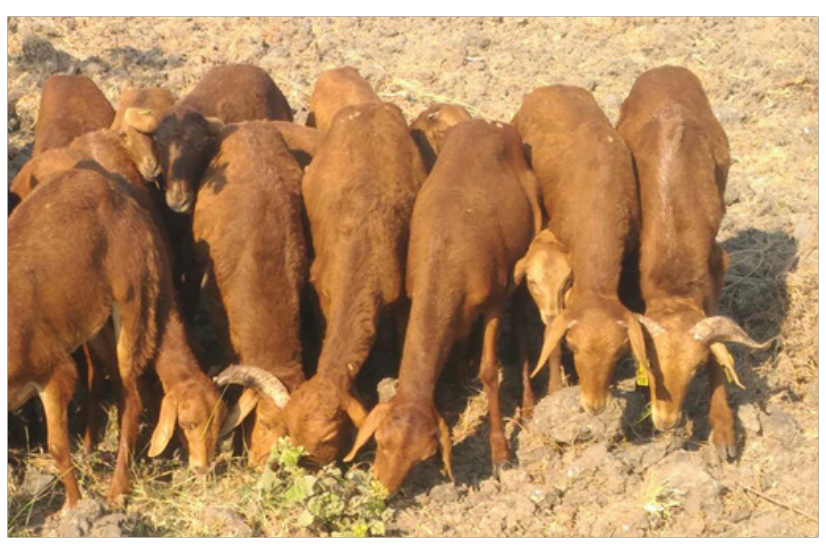

Figure I Nellore cross-breed sheep. 


\section{Materials and methods}

The present study was conducted at Department of Veterinary Clinical Complex, College of Veterinary Science, Proddatur, Andhra Pradesh from 2013 to 2016. Apparently healthy local crossbreed of sheep (Nellore) were categorized into five groups based on their age and in each group twenty sheep were included. Sheep were categorized into Group-I (below six months), Group-II (six months to one year), Group-III (one year to two years), Group-IV (two years to three years) and Group-V (above three years). The animals were examined prior to ECG recording and were proved to be clinically healthy. The electrocardiography was recorded on a bipolar base apex lead according to the standard and previous studies. Electrocardiography recording was done in a quiet standing position by using the alligator type electrode clips. The positive electrode of lead I (left arm) was placed on the skin of the fifth intercostals space caudal to the olecranon process, and the negative electrode (right arm) was attached over the jugular furrow about the lower $1 / 3$ of the neck on the left side. Methyl alcohol was applied before application of the electrode clips to the skin. ${ }^{6}$

All ECGs were recorded on a three-channel electrocardiographic machine (Marks electronics, Chennai) with the paper speed of $25 \mathrm{~mm} /$ $\mathrm{sec}$ and calibration of $10 \mathrm{~mm}$ equal to $1 \mathrm{mV}$. A magnifying glass was used for analyzing and measuring ECG parameters. The heart rate was calculated according to the R-R interval in lead-I and expressed in beats per minute (bpm). The amplitude of P, QRS and T waves was recorded for lead I and expressed in millivolt $(\mathrm{mV})$. Duration of $\mathrm{P}$ waves, PR interval, QRS complex, ST interval and T waves were calculated and expressed in seconds. The data were analyzed with the Statistical Package for the Social Sciences (SPSS) software and the data were expressed as mean \pm standard error (confidence interval $95 \%)$.

Table I Amplitude in mill volts of the lead-I of electrocardiography in sheep (Mean \pm SE)

\begin{tabular}{|c|c|c|c|c|c|c|}
\hline \multirow{2}{*}{ Parameters } & \multicolumn{5}{|c|}{ Different age groups of sheep } & \multirow{2}{*}{ 'F'value } \\
\hline & Group-1 & Group-2 & Group-3 & Group-4 & Group-5 & \\
\hline P Wave & $0.169 \pm 0.005$ & $0.171 \pm 0.005$ & $0.174 \pm 0.005$ & $0.173 \pm 0.005$ & $0.177 \pm 0.005$ & $0.279^{\mathrm{NS}}$ \\
\hline QRS Complex & $0.785^{\mathrm{a}} \pm 0.068$ & $0.685^{a} \pm 0.037$ & $0.982^{b} \pm 0.054$ & $0.947^{\mathrm{b}} \pm 0.048$ & $1.040^{\mathrm{b}} \pm 0.068$ & $6.852^{*}$ \\
\hline T Wave & $0.307^{a} \pm 0.010$ & $0.320^{a} \pm 0.008$ & $0.345^{\mathrm{a}} \pm 0.008$ & $0.402^{b} \pm 0.021$ & $0.415^{\mathrm{b}} \pm 0.018$ & $11.133^{*}$ \\
\hline
\end{tabular}

*Significant ( $\mathrm{P} \leq 0.05)$; NSNot significant $(\mathrm{P}>0.05)$

Table 2 Duration in seconds of the lead-I of electrocardiography in sheep (Mean \pm SE)

\begin{tabular}{|c|c|c|c|c|c|c|}
\hline \multirow{2}{*}{ Parameters } & \multicolumn{5}{|c|}{ Different age groups of sheep } & \multirow{2}{*}{ 'F' value } \\
\hline & Group-1 & Group-2 & Group-3 & Group-4 & Group-5 & \\
\hline P wave & $0.041 \pm 0.006$ & $0.055 \pm 0.008$ & $0.060 \pm 0.006$ & $0.050 \pm 0.003$ & $0.044 \pm 0.003$ & $0.158^{\mathrm{NS}}$ \\
\hline QRS Complex & $0.063 \pm 0.003$ & $0.064 \pm 0.003$ & $0.056 \pm 0.004$ & $0.067 \pm 0.002$ & $0.066 \pm 0.003$ & $0.138^{\mathrm{NS}}$ \\
\hline T Wave & $0.104 \pm 0.004$ & $0.104 \pm 0.005$ & $0.097 \pm 0.005$ & $0.086 \pm 0.004$ & $0.103 \pm 0.003$ & $0.021^{\mathrm{NS}}$ \\
\hline P-R Interval & $0.118^{\mathrm{a}} \pm 0.008$ & $0.139^{\mathrm{a}} \pm 0.011$ & $0.198^{\mathrm{b}} \pm 0.016$ & $0.191^{\mathrm{b}} \pm 0.012$ & $0.217^{\mathrm{b}} \pm 0.011$ & $0.000 * *$ \\
\hline Q-T Interval & $0.235^{\mathrm{a}} \pm 0.016$ & $0.232^{\mathrm{a}} \pm 0.017$ & $0.297^{\mathrm{ab}} \pm 0.020$ & $0.345^{\mathrm{bc}} \pm 0.038$ & $0.385^{\mathrm{c}} \pm 0.026$ & $0.000 * *$ \\
\hline Heart Rate (bpm) & $115.8^{\mathrm{d}} \pm 2.76$ & $106.2^{c} \pm 0.62$ & $90.2^{b} \pm 2.25$ & $86.8^{\mathrm{b}} \pm 0.81$ & $73.2^{\mathrm{a}} \pm 1.62$ & $0.000 * *$ \\
\hline
\end{tabular}

*Significant $(\mathrm{P} \leq 0.05)$; NSNot significant $(\mathrm{P}>0.05)$ 


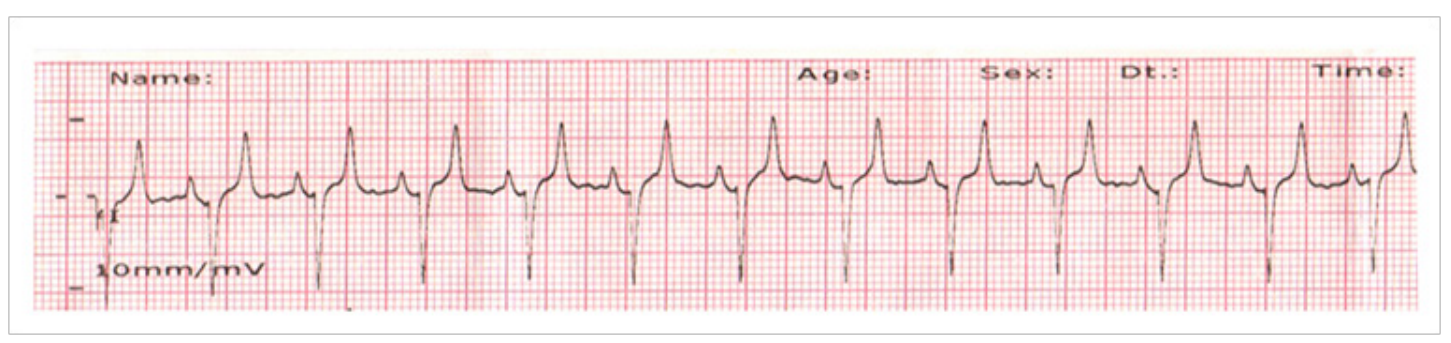

Figure 2Electrocardiogram of adult Nellore cross-breed sheep $(25 \mathrm{~mm} / \mathrm{sec}$ and $10 \mathrm{~mm} / \mathrm{ImV})$.

\section{Discussion}

No significant difference was found in $\mathrm{P}$ wave amplitude, duration of $\mathrm{P}$ wave, QRS complex and $\mathrm{T}$ wave. The heart rate, amplitude of ECG waves including QRS complex, T wave and duration of P-R, Q-T and R-R intervals showed the significant difference between the age groups. Heart rate was gradually decreased while aging and the negative correlation between age of the sheep and heart rate was noticed. While aging, significant reduction in the heart rate was noticed with a correlation. Variations in the heart rate of sheep were recorded different breeds of sheep and the difference in the size of the heart reflects the recording parameters as per the age advances in electrocardiography. The predominant negative correlation was noticed between the PR interval and the heart rate was noticed while aging. Chalmeh et al. ${ }^{4}$ reported the electrocardiography parameters in Chios breed as mean amplitude of $\mathrm{P}$ wave, QRS complex and T wave was in $0.052 \pm 0.016,0.054 \pm 0.012$ and $0.110 \pm 0.057 \mathrm{mV}$ respectively in Chios breed lambs and it was $0.055 \pm 0.010,0.059 \pm 0.018$ and $0.122 \pm 0.050 \mathrm{mV}$ respectively. These findings were within range of present study. Due to the smallest cardiac size and presence of more superficial purkinje fibers in lambs in comparison with ewes can create lowest durations and intervals in younger ones. It could be suggested that as the mass of heart in larger animals became larger in the process of growth, the duration of transfer of cardiac electrical activity also increases. ${ }^{7}$ Mean duration of $\mathrm{P}$ wave, QRS complex and T wave was within the range of other studies. ${ }^{8}$

Some of the undetectable conditions on clinical examination can be identified while electrocardiographic examination. Due to lack of normal reference values and electrocardiographic patterns in clinically healthy sheep, for a specific breed, can lead to failure in detection of different conditions which can influence the transmission of cardiac impulses. ${ }^{9}$ In the present study, a variation in between the different age group of sheep has noticed it is due to the presence of variation in the conductive properties of the body mass in the ruminants. ${ }^{10,11}$ Progressive increase in the body mass may cause difficulty in reaching the waves to the body surface due to relative electrical insulation by increasing body mass and the decrease of amplitude in adults. ${ }^{12}$ Due to the passing of high degree of synchronized ventricular polarization in different directions, amplitude of $\mathrm{P}, \mathrm{R}$ and $\mathrm{T}$ waves recorded in the study not followed specific pattern.

\section{Conclusion}

This study provides information on the cardiac rhythm, heart rate, duration, and amplitude of ECG deflections in one of the common sheep breed in the YSR District of Andhra Pradesh, India. While aging, heart rate, amplitude QRS complex, $\mathrm{T}$ wave and duration of P-R, Q-T and R-R intervals showed the significant difference between the age groups. It is important to compare the diseased animals or research trails in relation to the specific age group of sheep.

\section{Acknowledgements}

The authors are thankful to the authorities of Sri Venkateswara Veterinary University for providing the facilities to carry out the work.

\section{Conflict of interest}

The author declares no conflict of interest.

\section{References}

1. Sivajothi S, Rayulu VC, Malakondaiah P, et al. Detection of antibodies against Trypanosoma evansi in sheep by indirect Elisa in Rayalaseema region of Andhra Pradesh. Journal of Advanced Veterinary Research. 2014;4(3):88-92.

2. Reddy BS, Venkatasiva kumar R, Reddy LSSV, et al. Analysis of base apex lead electrocardiograms of adult buffaloes. JDVAR. 2015;2(6):00058.

3. Reddy BS, Sivajothi S. Electrocardiographic parameters of normal dairy cows during different ages. J Veter Sci Med. 2016;4(1):5.

4. Chalmeh A, Akhtar IS, Zarei MH, et al. Electrocardiographic indices of clinically healthy Chios sheep. Veterinary Science Development. 2015;5(2):99-102.

5. Radostits OM, Gay CC, Hinchcliff KW, et al. Diseases of the cardiovascular system. In Veterinary medicine: a Text Book of the Diseases of Cattle, Horses, Sheep, Pigs and Goats. 10th ed. Elsevier; 2007. p. 399-438.

6. Reddy BS, Reddy LSSV, Raju KGS, et al. Electrocardiographic studies in adult Osmanabadi goats. The journal of veterinary science. Photon. 2014;115:333-337.

7. Schmidt Nielsen K. Animal physiology: adaption and environment. 6th ed. USA: Cambridge University Press; 1997.

8. Torio Alvarez R, Cano Rabano M, Benedito Castellote LJ, et al. Comparison of two methods of electrocardiography in Gallega breed of sheep. Proceedings of the $18^{\text {th }}$ World Buiatrics Congress: 26th Congress of the Italian Association of Buiatrics, Italy; 1994. p. 1189-1192.

9. Sivajothi S, Reddy BS. Immature paramphistomosis in a sheep herd. International Journal of Biological Research. 2014;2(2):140142.

10. Milnor W. Aortic wavelength as a determinant of the relation between heart rate and body size in mammals. Ame J Physiol. 1979.237(1):R3-R6.

11. Kellerová E, Szathmáry V, Kozmann G. Spontaneous variability and reactive postural beat-to-beat changes of integral ECG body surface potential maps. Physiol Res. 2010;59(6):887-896.

12. Reddy BS, Sivajothi S. Vital and electrocardiographic parameters in domestic Newzealand white pet rabbits. International Journal of Livestock Research. 2017;7(10):86-91. 